\title{
Modification of Silica Rice Husk Ash to Solid Ammonium Sulphate for Second Generation Biofuels Productions
}

\author{
Kasim Mohammed Hello, ${ }^{1}$ Majid Jari Mohammed, ${ }^{2}$ Asstabraq Mohsen Yasser, ${ }^{2}$ \\ Farook Adam, ${ }^{3}$ and Zinab Farag ${ }^{3}$ \\ ${ }^{1}$ Chemistry Department, College of Science, Al-Muthanna University, Iraq \\ ${ }^{2}$ Chemistry Department, College of Science, Kufa University, Iraq \\ ${ }^{3}$ School of Chemical Sciences, University Sains Malaysia, 11800 Penang, Malaysia \\ Correspondence should be addressed to Kasim Mohammed Hello; kasimhello@gmail.com
}

Received 25 August 2014; Revised 18 October 2014; Accepted 23 October 2014; Published 9 December 2014

Academic Editor: Mohammed M. Bettahar

Copyright (C) 2014 Kasim Mohammed Hello et al. This is an open access article distributed under the Creative Commons Attribution License, which permits unrestricted use, distribution, and reproduction in any medium, provided the original work is properly cited.

\begin{abstract}
A new approach has been demonstrated for the synthesis of solid ammonium sulphate attached to silica rice husk ash. The 3(aminopropyl)triethoxysilane was immobilized onto silica at room temperature to functionalize the silica with ammine end groups $\left(-\mathrm{NH}_{2}\right)$. The amine group was sulphated with sulphuric acid to produce a novel micro-rod-like shaped acidic catalyst (as seen with TEM) designated $\mathrm{RHNH}_{3} \mathrm{SO}_{4} \mathrm{H}\left(\mathrm{RH}=\right.$ rice husk). The TGA analysis shows that the catalyst is stable at temperatures below $200^{\circ} \mathrm{C}$. The acidity measurement of the catalyst indicates that it has Brønsted acid sites. Cellulose extracted from waste of rice husk and cellulose extracted from office paper were hydrolysed to glucose in $6 \mathrm{~h}$, and the glucose was hydrolysed afterwards to other products within $13 \mathrm{~h}$. The catalyst is reusable many times without a significant loss of catalytic activity.
\end{abstract}

\section{Introduction}

Until recently, most ionic catalysts were synthesised and used for different purposes in liquid solutions. These ionic liquids were showing very good catalytic activity compared with the commercial strong acids such as $\mathrm{H}_{2} \mathrm{SO}_{4}, \mathrm{HCl}$, and $\mathrm{H}_{3} \mathrm{PO}_{4}$, which have limitations due to a tedious work-up procedure and the necessity of postneutralization of the strongly acidic media leading to production of undesired wastes. Therefore many challenges are facing the researcher regarding the characterization and the recycling of these ionic liquid catalysts. We have recently reported the synthesis of a new type of ionic catalysts in solid state form with less environmental concerns. Those catalysts are recyclable and can be used for the same purposes as where the ionic liquids catalysts are used [1].

Rice husk (RH) is a major by-product of the rice-milling industries and it is causing disposal problems. Moreover, after its burning approximately $20 \%$ ash content comprises over $95 \%$ of amorphous silica which has very fine particle size, very high purity, high surface area, and high porosity. These properties would give rice husk utilization a very economically attractive perspective $[2,3]$. One important application of silica is due to its ability to be modified with different silylating agents, which can introduce basic groups through an anchored pendant chain. The traditional procedure for immobilization of 3-(aminopropyl)triethoxysilane (APTES) onto different types of silica involves long reaction times, nonenvironmentally friendly organic solvents, harsh refluxing condition, and multiple steps [4-6]. Moreover, the vast majorities of these protocols call for expensive chemicals and techniques and cause environmental pollution. A more direct and simple method was introduced by us to immobilize APTES onto silica to give a $-\mathrm{CH}_{2}-\mathrm{NH}_{2}$ functionality on the silica surface $[7,8]$.

Recently, a new technique has been developed towards the production of second generation $(2 \mathrm{G})$ biofuels without the use of expensive enzymes [9]. Producing 2G bioethanol from dead plant tissue is environmentally friendly, but it is also currently expensive because the process that is used 
today needs expensive enzymes. The goal is to produce bioethanol from cellulose containing waste plant parts. Cellulose is the major polymeric component of plant material and is the most abundant polysaccharide on Earth. In nature, a variety of microorganisms are known for producing a set of enzymes capable of degrading this normally insoluble polymer to soluble sugars, primarily cellobiose and glucose [10]. As cellulose is very difficult to break down, it cannot directly be used as a food source. Cellulose is found everywhere in nature in rich quantities, for example, in the stems of the corn plant, rice husk, and palm fronds. If we can produce bioethanol from the corn stems and keep the corn cubs for food, we have probably come a long way to make biofuel production more acceptable. In fact we can now report about an entirely new molecular compound, which can also replace enzymes in the work of breaking down cellulose to sugar for the production of $2 \mathrm{G}$ biofuels, following up on the procedures leading to the earlier reported sulfonic acid compound [9].

\section{Materials and Methods}

2.1. Raw Materials. The chemicals used in this study were sodium hydroxide (Systerm, 99\%), acetone (GCC, 99\%), 3-(aminopropyl)triethoxysilane (Merck, 98\%), nitric acid (Scharlau, 65\%), 1-butanol (Fluka, 99\%), cellulose (Riedle-De Haen, 99\%), cyclohexanol (Riedle-De Haen, 99\%), cyclohexanone (Riedle-De Haen, 99\%), dimethylformamide (DMF) (Systerm, 99\%), dinitrosalicylic acid (DNS) (BDH, 99\%), glucose (BDH, 99\%), lithium chloride (Sigma, 99\%), sodium chloride (Sigma, 99\%), potassium chloride (Sigma, 99\%), sulphuric acid (Poch, 95\%), potassium chloride (Sigma, 99\%), and sulphuric acid (Poch, 95\%). The rice husks (RH) were collected from a rice mill in Samawah, Iraq. All other chemicals used were AR grade or of high purity and were used directly without further purification.

2.2. Sources of Silica. The rice husk ash (RHA) was chosen as the source of amorphous silica as it was available in abundance. The silica was extracted from rice husk using a previously reported method $[11,12]$.

\subsection{Sources of Cellulose}

2.3.1. Extraction of Cellulose from $R H$. $\mathrm{RH}$ was used as a source of cellulose as well as of silica. The cellulose was extracted from RH according to the method reported in [13]. In general the RH was washed twice with water and dried at room temperature for $24 \mathrm{~h}$. A weight of $35 \mathrm{~g}$ of the cleaned RH was stirred with $700 \mathrm{~mL}$ of $1.0 \mathrm{M}$ nitric acid at room temperature for $24 \mathrm{~h}$ and washed with distilled water. The wet material was subsequently dried in an oven at $100^{\circ} \mathrm{C}$ for $24 \mathrm{~h}$. The rice husk treated with acid was weighed and then transferred into a $1.0 \mathrm{~L}$ plastic container. To purify the cellulose by removing silica and lignin from RH fibres, $500 \mathrm{~mL}$ of $1.0 \mathrm{M}$ sodium hydroxide solution was added. Then the solution was stirred for $24 \mathrm{~h}$ at room temperature. It was then filtered using suction filtration. The dark brown filtrate (sodium silicate solution with lignin) was kept in a covered plastic container. The solid was filtered and washed several times using distilled water. The solid was treated with $6.0 \mathrm{M} \mathrm{NaOH}$ for $6 \mathrm{~h}$ and then filtered to be used for cellulose extraction. The filtrate was titrated with acid at room temperature using $5.0 \mathrm{M}$ sulphuric acid under continuous stirring until constant $\mathrm{pH}$ in the range of 5-6 was reached. The resulting suspension with hydrolysed material was then separated by vacuum filtration and washed roughly with distilled water. This method gives $6.0 \mathrm{~g}, 17.14 \%$ of cellulose.

2.3.2. Extraction of Cellulose from Waste Paper. Waste paper was also used as raw material for extraction of cellulose by a simple and economic method. Waste paper was collected from waste boxes of the offices in Al-Muthanna University. The cellulose was extracted from $\mathrm{RH}$ according to the method reported in [13]. In general, $5.0 \mathrm{~g}$ of waste paper was cut into small pieces and mixed with sodium hydroxide solution $7.5 \%$ in a plastic container equipped with stirrer. The mixture was stirred for $6 \mathrm{~h}$ and then filtered. The filtrate was titrated against $5.0 \mathrm{M}$ sulphuric acid solution until the $\mathrm{pH}$ reached 5.0. After separating the mixture, the solid was washed with distilled water and dried at room temperature. This method gave about $1.0 \mathrm{~g}, 20 \%$ of cellulose.

2.4. Synthesis of $\mathrm{RHNH}_{3} \mathrm{SO}_{4} \mathrm{H}$ Catalyst. The APTES was functionalization onto RHA to produce $\mathrm{RHAPrNH}_{2}$ according to the method reported elsewhere [7]. The primary amine in $\mathrm{RHAPrNH}_{2}$ was sulphated to the solid ammonium sulphate at room temperature. In general, $25 \mathrm{~mL}$ of $0.05 \mathrm{M}$ sulphuric acid was added to the $2.0 \mathrm{~g}$ of dry $\mathrm{RHAPrNH}_{2}$ in a $50 \mathrm{~mL}$ round bottom flask and it was stirred for $24 \mathrm{~h}$. The solid ammonium sulphate formed was filtered and washed with copious amount of water and then dried in an oven at $100^{\circ} \mathrm{C}$ for $24 \mathrm{~h}$. The resulting compound was labelled as $\mathrm{RHNH}_{3} \mathrm{SO}_{4} \mathrm{H}$. About $1.9 \mathrm{~g}$ was collected using this method.

2.5. The Surface Acidity of $\mathrm{RHNH}_{3} \mathrm{SO}_{4} \mathrm{H}$. The surface acidity measurement of $\mathrm{RHNH}_{3} \mathrm{SO}_{4} \mathrm{H}$ was done as in the method reported in [2]. In general $\mathrm{RHNH}_{3} \mathrm{SO}_{4} \mathrm{H}$ together with a beaker containing pyridine was placed in a desiccators equipped with a valve connected to a membrane vacuum pump (AMB Greiffenberger Antriebstechnik, MZ2C, CE 2002/06). The system was evacuated for $1 \mathrm{~h}$ at a rate of $1.7 \mathrm{~m}^{3} \mathrm{~h}^{-1}$. The system was kept under sealed vacuum for $48 \mathrm{~h}$. The atmosphere in the desiccators was then evacuated again for $1 \mathrm{~h}$ at the same pump rate. Then, the solid compound was removed and analyzed by FT-IR on a $\mathrm{KBr}$ disc.

\subsection{Catalytic Hydrolysis Procedure}

2.6.1. Hydrolysis of Cellulose. The cellulose hydrolysis was carried out in the liquid phase in a $50 \mathrm{~mL}$ round bottom flask equipped with magnetic stirrer and water condenser connected to the chillier to control the water temperature in between 10 and $15^{\circ} \mathrm{C} .20 \mathrm{~mL}$ of DMF, $0.2 \mathrm{~g}$ of $\mathrm{LiCl}$, and $0.18 \mathrm{~g}$ cellulose were separately transferred to the round bottom flask containing $150 \mathrm{mg}$ of the catalyst (predried at $110^{\circ} \mathrm{C}$ for $24 \mathrm{~h}$ and cooled in desiccators to minimize moisture content). The hydrolysis temperature was fixed at $120^{\circ} \mathrm{C}$. The hydrolysis 
mixture was refluxed for $13 \mathrm{~h}$. A $0.5 \mathrm{~mL}$ portion of the clear hydrolyte solution from the reaction mixture was transferred into a vial and $2.0 \mathrm{~mL}$ of deionized water was added. To this solution were added $2.0 \mathrm{~mL}$ of DNS reagent and $2.0 \mathrm{~mL}$ of $2.0 \mathrm{~N} \mathrm{NaOH}$ and the mixture was incubated in a water bath maintained at $90^{\circ} \mathrm{C}$ for $5 \mathrm{~min}[14,15]$. The DNS reagent was prepared according to IUPAC method [16]. The reagent blank sample was prepared with $2.0 \mathrm{~mL}$ of deionized water, $2.0 \mathrm{~mL}$ of DNS reagent, and $2.0 \mathrm{~mL}$ of $2.0 \mathrm{~N} \mathrm{NaOH}$ and heated similarly to the other samples. Then the absorbance was measured at $540 \mathrm{~nm}$, against the reagent blank, and glucose concentrations in the solutions were estimated by employing a standard curve prepared using glucose. The catalytic activity with different mass of catalyst $(50,100$, 150,200 , and $500 \mathrm{mg}$ ), different temperatures (100, 110, and $120^{\circ} \mathrm{C}$ ), different solvents, (i.e., 1-butanol, cyclohexanol, and cyclopentanone), and different solvent salt mixtures $(\mathrm{LiCl}$, $\mathrm{NaCl}$, and $\mathrm{KCl}$ ) was studied by using the same procedure as described above.

2.6.2. The Reusability of the Catalyst. Reusability experiments were conducted by running the hydrolysis successively with the same catalyst under the same hydrolysis conditions. The hydrolysis was first run with the fresh catalyst to complete conversion and then the catalyst was filtered and washed with hot dioxane and then with a hot mixture of DMF and $\mathrm{LiCl}$ and dried at $130^{\circ} \mathrm{C}$. After regeneration, the catalysts were reused under the optimised reaction conditions.

2.6.3. Hydrolysis Procedure for Homogenous Catalyst. The hydrolysis using the homogenous catalyst was studied with ammonium sulphate. Typically, a $50 \mathrm{~mL}$ capacity twonecked round-bottom flask, equipped with a magnetic stirrer (700 rpm) and water condenser, was used. $20 \mathrm{~mL}$ of DMF was transferred by pipette into the round bottom flask containing $4.6 \mathrm{mmol}$ of ammonium sulphate. After the reaction temperature reached $120^{\circ} \mathrm{C}, 0.18 \mathrm{~g}$ of cellulose was added. The hydrolysis mixture was refluxed. Samples for analysis $(\sim 0.50 \mathrm{~mL})$ were withdrawn at regular intervals from the hydrolysis mixture by means of a syringe equipped with filter (cotton wool). To this solution $2.0 \mathrm{~mL}$ of DNS reagent and $2.0 \mathrm{~mL}$ of $2.0 \mathrm{~N} \mathrm{NaOH}$ were added and the mixture was incubated in a water bath maintained at $90^{\circ} \mathrm{C}$ for $5 \mathrm{~min}$. The glucose concentrations in solutions were calculated by employing a standard curve prepared using glucose.

2.7. Sample Characterization. The prepared $\mathrm{RHNH}_{3} \mathrm{SO}_{4} \mathrm{H}$ was characterized by elemental analysis (Perkin Elmer Series II, 2400), thermogravimetric analyses (TGA SDTA851 ${ }^{\mathrm{e}}$ ), from 30 to $900^{\circ} \mathrm{C}$ at a heating rate of $20^{\circ} \mathrm{C} \mathrm{min}^{-1}$ under nitrogen flow. Powder X-ray diffraction (Siemens Diffractometer D5000, Kristalloflex), nitrogen adsorption porosimetry (Automatic Physisorption Autosorb-1 CLP, Quantachrome, USA), FT-IR spectroscopy (Perkin-Elmer System 2000), scanning electron microscopy (SEM) (Leica Cambridge S360), and energy dispersive spectrometry, EDX (Edax Falcon System), were all used as well. The TEM micrographs were obtained using Philips CM12 equipment.
TABLE 1: The chemical analysis of RHA, RHAPrNH$H_{2}$, and $\mathrm{RHNH}_{3} \mathrm{SO}_{4} \mathrm{H}$ using a combination of elemental and EDX analysis.

\begin{tabular}{lccccc}
\hline \multirow{2}{*}{ Sample } & \multicolumn{5}{c}{ Elemental analysis (\%) } \\
& $\mathrm{C}$ & $\mathrm{H}$ & $\mathrm{N}$ & $\mathrm{S}$ & $\mathrm{Si}$ \\
\hline $\mathrm{RHA}$ & $0.42(6.76)$ & 1.76 & - & - & $(29.09)$ \\
$\mathrm{RHAPrNH}_{2}[7]$ & $9.67(19.52)$ & 2.31 & $6.08(6.1)$ & - & $(23.48)$ \\
$\mathrm{RHNH}_{3} \mathrm{SO}_{4} \mathrm{H}$ & $10.07(20.79)$ & 2.99 & $2.20(3.43)$ & $-(3.52)$ & $(23.45)$ \\
\hline
\end{tabular}

\section{Results and Discussion}

The amine group $\left(-\mathrm{NH}_{2}\right)$ in the $\mathrm{RHAPrNH}_{2}$ was sulphated with sulphuric acid via a simple procedure at room temperature to produce a novel microstructure acidic catalyst $\mathrm{RHNH}_{3} \mathrm{SO}_{4} \mathrm{H}$. The schematic representation for the synthesis of $\mathrm{RHNH}_{3} \mathrm{SO}_{4} \mathrm{H}$ is shown in Scheme 1 .

3.1. CHN Analysis. Table 1 shows the chemical analysis of RHA, RHAPrNH ${ }_{2}$ [7], and $\mathrm{RHNH}_{3} \mathrm{SO}_{4} \mathrm{H}$. The analysis was carried out by a combination of elemental and EDX methods (presented between brackets). The combined analyses show that sulphur and nitrogen are exhibited in $\mathrm{RHNH}_{3} \mathrm{SO}_{4} \mathrm{H}$, while only nitrogen is found in $\mathrm{RHAPrNH}_{2}$. None of these elements were found in RHA, as was expected. The relative concentration values for silicon were much lower than in the starting RHA, which shows that a successful incorporation or attachment of new elements to the silica matrix has taken place.

3.2. Infrared Spectroscopy Analysis. Figure 1 shows the FTIR spectra of $\mathrm{RHAPrNH}_{2}, \mathrm{RHNH}_{3} \mathrm{SO}_{4} \mathrm{H}$, and its difference spectrum. The strong and broad band in the range 3500$3400 \mathrm{~cm}^{-1}$ region corresponds to the hydrogen bonded $\mathrm{Si}-$ $\mathrm{OH}$ groups. The $\mathrm{RHAPrNH}_{2}$ and the difference spectra show bands at $3153 \mathrm{~cm}^{-1}$ corresponding to the free $\mathrm{NH}_{2}$ [17] and a weak band at $2939 \mathrm{~cm}^{-1}$ corresponding to the aliphatic $\mathrm{C}-\mathrm{H}$ stretching. The strong band at $1384 \mathrm{~cm}^{-1}$ is related to the $\mathrm{NO}_{3}{ }^{-}$ions. The $\mathrm{RHAPrNH}_{2}$ treated with $\mathrm{H}_{2} \mathrm{SO}_{4}$ showed some changes on the FT-IR spectrum. The band at $3153 \mathrm{~cm}^{-1}$ (corresponding to the free $\mathrm{NH}_{2}$ ) disappeared. This indicates the successful transformation of $-\mathrm{NH}_{2}$ group to $-\mathrm{NH}_{3}$ group. However, we also observe the disappearance of the strong band at $1384 \mathrm{~cm}^{-1}$ (for nitrate ion), which may be due to a replacement by $-\mathrm{SO}_{4} \mathrm{H}$ ions. This fact was confirmed by appearance of two bands at 1308 and $1162 \mathrm{~cm}^{-1}$, assigned to the presence of the $\mathrm{SO}_{2}$ group which is the main component of $-\mathrm{SO}_{4} \mathrm{H}$ group [9].

The RHA spectrum (not shown) does not show these bands. In RHA the Si-O-Si vibration appears at $1082 \mathrm{~cm}^{-1}$. This band was observed to shift to $1067,1054 \mathrm{~cm}^{-1}$ in $\mathrm{RHAPrNH}_{2}$ and $\mathrm{RHNH}_{3} \mathrm{SO}_{4} \mathrm{H}$, respectively.

3.3. Powder X-Ray Diffraction (XRD) and Nitrogen Adsorption Analysis. The XRD pattern (not shown) did not show sharp diffraction patterns. This is an indication that the sample is 


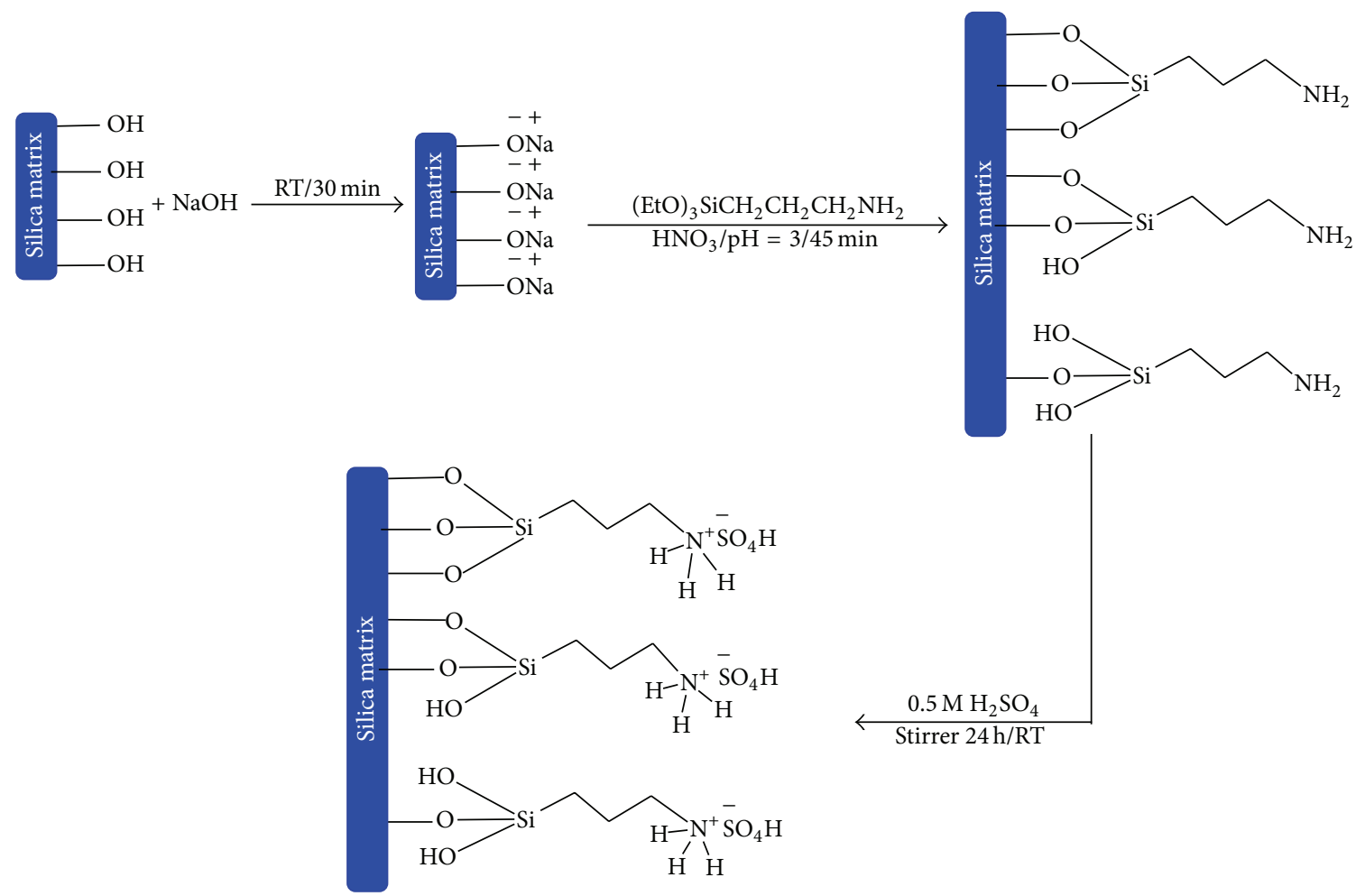

Scheme 1: The reaction sequence and the possible structures for $\mathrm{RHAPrNH}_{2}$ and $\mathrm{RHNH}_{3} \mathrm{SO}_{4} \mathrm{H}$. The approximate times taken for the completion of the experimental process are also shown. The whole process of dissolution and immobilization was done at room temperature (RT).

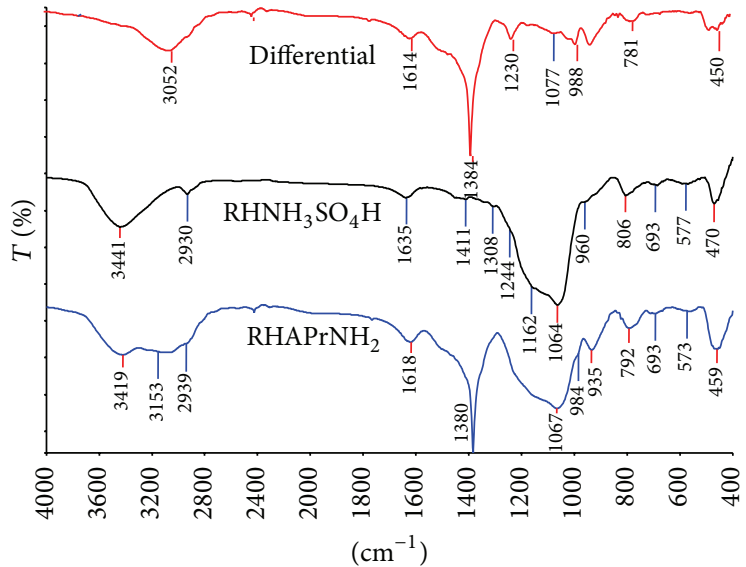

FIGURE 1: The FT-IR spectra of RHAPrNH $2, \mathrm{RHNH}_{3} \mathrm{SO}_{4} \mathrm{H}$, and the difference spectrum.

amorphous. A broad diffraction band at $2 \theta$ angle of ca. $22^{\circ}$ was observed which is typical for amorphous silica.

Figure 2 shows the nitrogen adsorption isotherm obtained for $\mathrm{RHNH}_{3} \mathrm{SO}_{4} \mathrm{H}$ and inset is shown in the pore size distribution graph. The hysteresis loop observed in the range of $0.4<P / P_{0}<1.0$ is associated with capillary condensation according to the IUPAC classification. The isotherm shown is type IV and exhibited an H3 hysteresis loop [19].

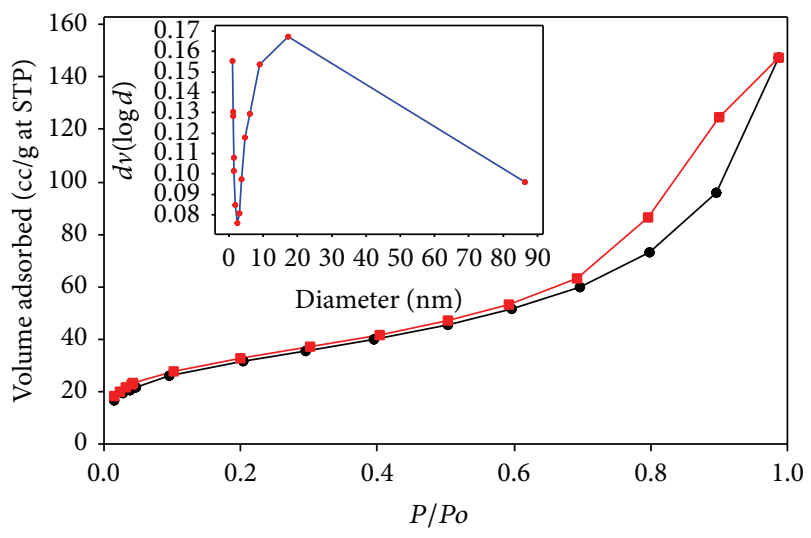

FIGURE 2: The $\mathrm{N}_{2}$ adsorption/desorption isotherms of $\mathrm{RHNH}_{3} \mathrm{SO}_{4} \mathrm{H}$ with the corresponding pore size distribution graph.

The BET analysis showed a specific surface area of $\mathrm{RHNH}_{3} \mathrm{SO}_{4} \mathrm{H}$ was $113 \mathrm{~m}^{2} \mathrm{~g}^{-1}$, while the specific surface area of RHAPrNH${ }_{2}$ was reported to be $1.32 \mathrm{~m}^{2} \mathrm{~g}^{-1}$ [7]. The increase in the surface area of $\mathrm{RHNH}_{3} \mathrm{SO}_{4} \mathrm{H}$ could be due to the use of $\mathrm{H}_{2} \mathrm{SO}_{4}$, which may remove the entire nitrate ion (as it is shown in FT-IR) and reduce the crowding on the surface and thus lead to opening the pores. The $\mathrm{RHNH}_{3} \mathrm{SO}_{4} \mathrm{H}$ (Figure 2) showed a broad pore size range from 5 to $90 \mathrm{~nm}$ with an average pore volume of $0.22 \mathrm{cc} \mathrm{g}^{-1}$, which is in the mesoporous range. 


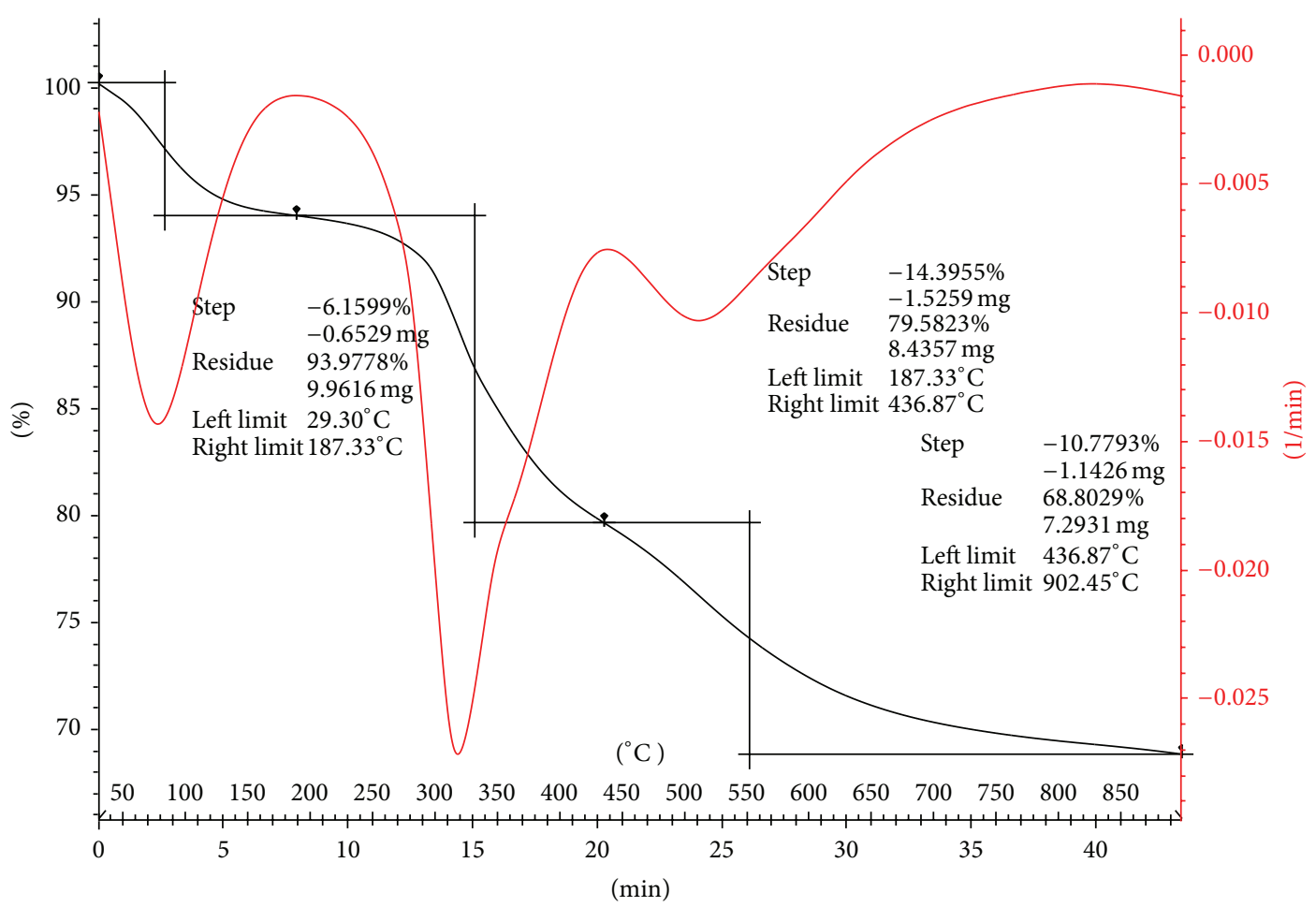

FIgURE 3: Thermogravimetric analysis (TGA)/differential thermal analysis (DTA) curves of $\mathrm{RHNH}_{3} \mathrm{SO}_{4} \mathrm{H}$.

3.4. Thermogravimetric Analysis (TGA)/Differential Thermal Analysis (DTA). Figure 3 shows the TGA-DTA of $\mathrm{RHNH}_{3} \mathrm{SO}_{4} \mathrm{H}$. The graph shows four characteristic decomposition stages. The first weight loss (ca. 6.2\%) is due to the loss of adsorbed water, and the second mass loss (ca. 14.4\%) is due to the decomposition of the aminopropyl sulphate groups anchored to the silica. According to this mass loss we found that $0.046 \mathrm{mmol} / \mathrm{g}$ of aminopropyl sulphate had been loaded onto $\mathrm{RHNH}_{3} \mathrm{SO}_{4} \mathrm{H}$. This value was in agreement with our pervious study with other ligands [20]. The slow, continuous weight loss (ca. 10.8\%) was due to the condensation of silanol groups at higher temperatures.

In the DTA curve in Figure 3 three exothermic transformations were observed. The first peak occurs between 29 and $187^{\circ} \mathrm{C}$, with a maximum at $75^{\circ} \mathrm{C}$, the second occurs between 187 and $436^{\circ} \mathrm{C}$, with a maximum at $330^{\circ} \mathrm{C}$, and the third occurs between 436 and $902^{\circ} \mathrm{C}$ with a maximum at $520^{\circ} \mathrm{C}$. The first exothermic change is due to the loss of adsorbed water, while the second and third are attributed to the arrangement of the structure of the polymer [21].

3.5. The SEM and TEM Analysis. The SEM micrographs at different magnifications are shown in Figure 4. These show the presence of a porous surface. The porosity is directly linked to the high specific surface area determined by the nitrogen adsorption studies. However, the SEM shows small particles with a bright, smooth surface. The smoothness of these particles is emphasized at the higher magnifications. These SEM micrographs are probably in good agreement with the BET analysis with regard to the specific surface area and specific pore volumes.
The TEM micrographs at different magnifications are shown in Figure 5. The $\mathrm{RHNH}_{3} \mathrm{SO}_{4} \mathrm{H}$ has rod-like morphology, and the diameters of the microrods are in the range of $0.1 \mu \mathrm{m}$ to $0.26 \mu \mathrm{m}$ and the length is about several millimetres.

3.6. Pyridine Adsorption Studies. The pyridine adsorption study of $\mathrm{RHNH}_{3} \mathrm{SO}_{4} \mathrm{H}$ obtained before and after pyridine adsorption in the region of $1700-1400 \mathrm{~cm}^{-1}$ (as shown in Sup. 1 in the Supplementary Material available online at http://dx.doi.org/10.1155/2014/128547). By comparing the two FT-IR spectra, after and before the pyridine test, two new bands in the regions $1544 \mathrm{~cm}^{-1}$ and $1489 \mathrm{~cm}^{-1}$ have been observed. These two bands indicate the presence of Brønsted acid sites [22].

3.7. Hydrolysis of Cellulose over $\mathrm{RHANH}_{3} \mathrm{SO}_{4} \mathrm{H}$ Catalyst. The $\mathrm{RHNH}_{3} \mathrm{SO}_{4} \mathrm{H}$ was used to hydrolyze cellulose in a liquid-phase reaction. Various parameters were evaluated to optimize the hydrolysis conditions on the fully completed cellulose hydrolysis, such as the effect of hydrolysis time, mass of catalyst, temperature, solvent effects, and salt effects.

3.7.1. Influence of Hydrolysis Time. The effect of the hydrolysis time on the hydrolysis of cellulose to glucose over $\mathrm{RHNH}_{3} \mathrm{SO}_{4} \mathrm{H}$ and homogenous ammonium sulphate $\left(\mathrm{NH}_{4}\right)_{2} \mathrm{SO}_{4}$ [18] is shown in Figure 6. The hydrolysis was carried out with $150 \mathrm{mg}$ catalyst using a $\mathrm{DMF} / \mathrm{LiCl}$ as a solvent at $120^{\circ} \mathrm{C}$. The initial hydrolysis of cellulose to glucose during the first hour was $65 \%$ and it reached the maximum hydrolysis of $98 \%$ in $6 \mathrm{~h}$. The homogeneous ammonium 

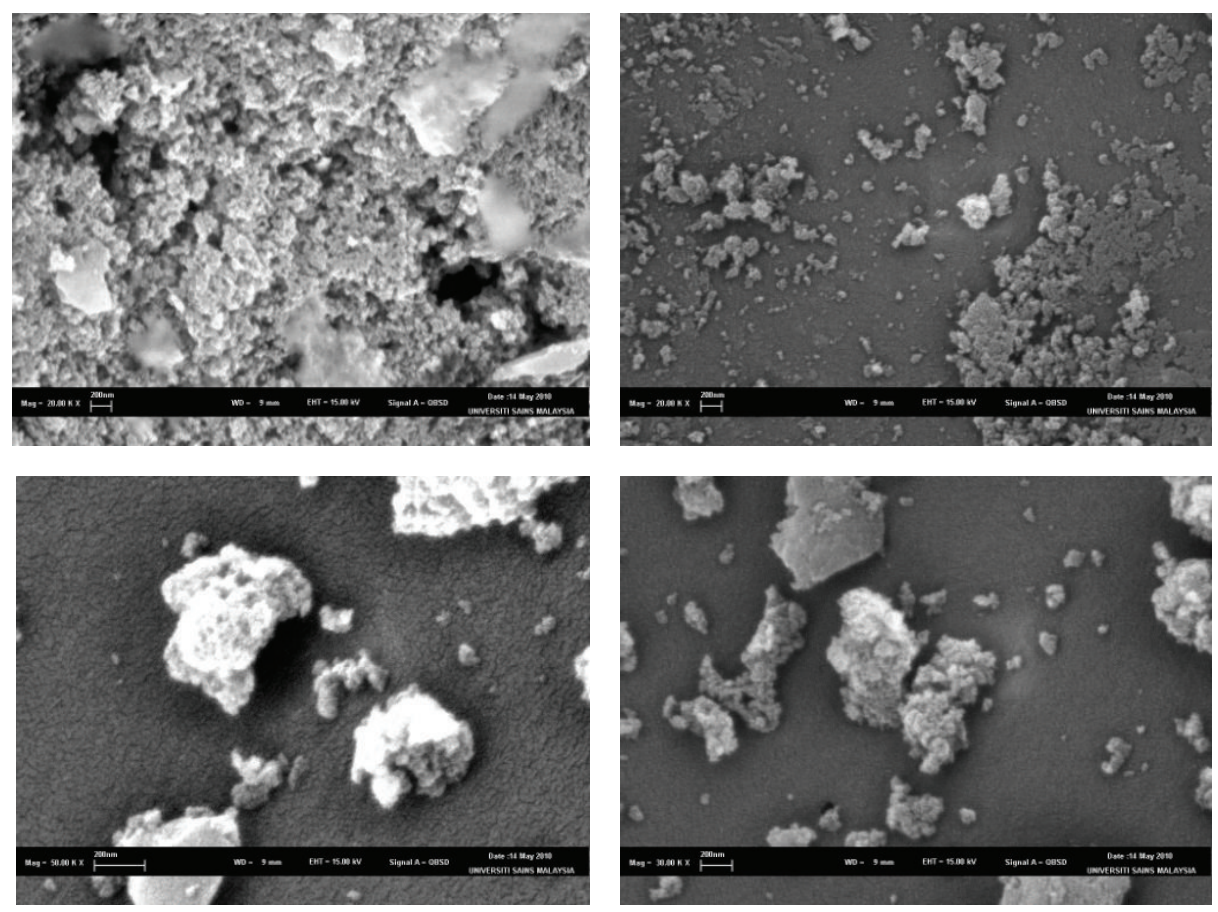

FIgURE 4: The SEM micrographs of the $\mathrm{RHNH}_{3} \mathrm{SO}_{4} \mathrm{H}$.

sulphate $(4.6 \mathrm{mmol} / \mathrm{g})$ showed $99 \%$ of glucose at $4 \mathrm{~h}$ and then the hydrolysis was decreased due to the hydrolysis of glucose itself. It was well known that the homogenous catalyst is more effective than the heterogeneous one. The hydrolysis of cellulose over ammonium sulphate was reaching the optimum after $4 \mathrm{~h}$ of hydrolysis time after which it decreases due to the hydrolysis of the glucose to other products. The hydrolysis of cellulose over $\mathrm{RHNH}_{3} \mathrm{SO}_{4} \mathrm{H}$ was reaching the optimum after $6 \mathrm{~h}$ of hydrolysis time. At this point the behaviour of both catalysts is the same. The only difference is processing time. After the optimum time of the cellulose hydrolysis over $\mathrm{RHNH}_{3} \mathrm{SO}_{4} \mathrm{H}$, the glucose would start to hydrolyze to other products too. It was observed that the cellulose was fully hydrolysed to glucose after $6 \mathrm{~h}$ and the glucose itself was hydrolyzed to other products during the next $6 \mathrm{~h}$. The selectivity of the hydrolysis of cellulose to glucose was $100 \%$ at the first $6 \mathrm{~h}$ of the hydrolysis. The advantages of using $\mathrm{RHNH}_{3} \mathrm{SO}_{4} \mathrm{H}$ as a catalyst in the hydrolysis of cellulose are the easy of recover and the repeatedly.

3.7.2. Effect of the Catalyst Mass. The hydrolysis of cellulose was carried out by varying the amount of $\mathrm{RHNH}_{3} \mathrm{SO}_{4} \mathrm{H}$ between 50 and $500 \mathrm{mg}$ at $120^{\circ} \mathrm{C}$. The effect of the amount of the catalyst on the hydrolysis of cellulose to glucose is shown in Figure 7. When the catalyst mass was increased from 50 to $150 \mathrm{mg}$, the cellulose hydrolysis increased from 68 to $98 \%$. Further increase of the catalyst mass had no significant effect. The increase in the conversion with catalyst mass could probably attribute to the availability of a greater number of catalytically active sites. Therefore $150 \mathrm{mg}$ was chosen as the optimum mass of the catalyst.
3.7.3. Influence of Hydrolysis Temperature. The effect of temperature on the hydrolysis of cellulose over $\mathrm{RHNH}_{3} \mathrm{SO}_{4} \mathrm{H}$ is shown in Figure 8. The hydrolysis increased when the reaction temperature was increased from 100 to $120^{\circ} \mathrm{C}$. The hydrolysis was ca. $99 \%$ at $120^{\circ} \mathrm{C}$. Most researchers set the hydrolysis temperature at $100^{\circ} \mathrm{C}$. To confirm the effect of hydrolysis temperature on the yield of glucose, we are comparing with our previous study on $\mathrm{SO}_{3} \mathrm{H}$-functionalized silica catalyst for cellulose hydrolysis to glucose [9]. The maximum glucose yields at $100^{\circ} \mathrm{C}$ were $80 \%$ after $8 \mathrm{~h}$ when our previous catalyst used $\mathrm{SO}_{3} \mathrm{H}$-functionalized silica. $\mathrm{By}$ using $\mathrm{RHNH}_{3} \mathrm{SO}_{4} \mathrm{H}$ the glucose yield was reaching $\approx 92 \%$ at $100^{\circ} \mathrm{C}$ and $98 \%$ at $120^{\circ} \mathrm{C}$ in $6 \mathrm{~h}$. This clearly indicates that the use of $\mathrm{RHNH}_{3} \mathrm{SO}_{4} \mathrm{H}$ is more effective to promote the hydrolysis of cellulose.

3.7.4. Influence of the Solvents System Effects. In this study it is found that the cellulose was highly soluble in DMF and cyclohexanol containing $\mathrm{LiCl}$. This is similar to previous findings studying other catalysts [9]. The effect of the solvent on the hydrolysis of cellulose over $\mathrm{RHNH}_{3} \mathrm{SO}_{4} \mathrm{H}$ was shown in Table 2. The hydrolysis was studied over different solvents, that is, cyclohexanol, cyclohexanone, and 1-butanol as well as DMF. All these solvents contain LiCl. It was observed that the hydrolysis of cellulose over these solvents was increased according the following order:

cyclohexanol $\approx$ DMF $>$ cyclopentanone $>1$-butanol.

The solvent-metal chloride interaction was also studied by using different metal chlorides, that is, $\mathrm{LiCl}, \mathrm{NaCl}$, and $\mathrm{KCl}$ in DMF. It was observed that the hydrolysis of cellulose 

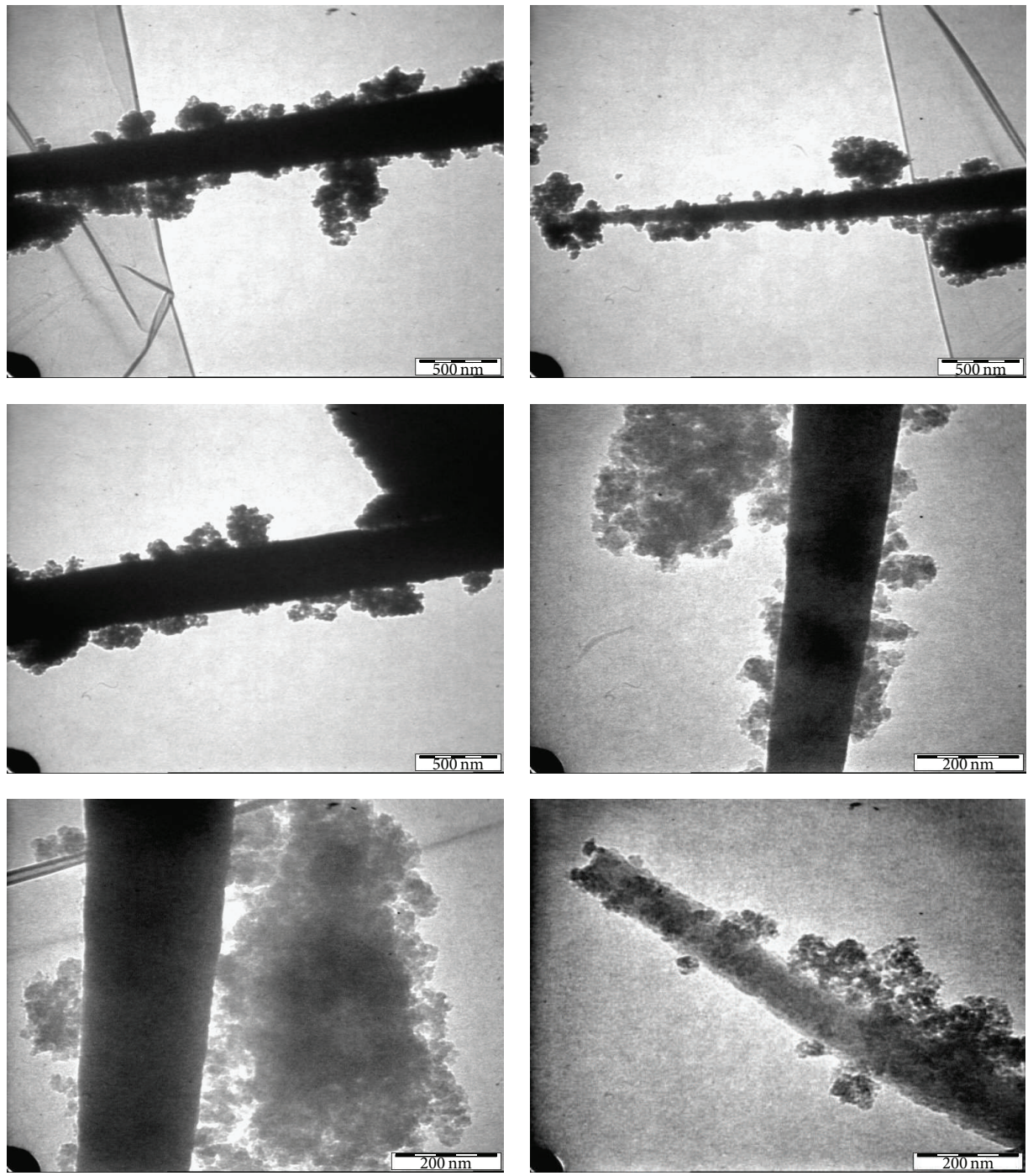

FIgURE 5: The TEM images of $\mathrm{RHNH}_{3} \mathrm{SO}_{4} \mathrm{H}$, at different magnification.

TABLE 2: The effect of different parameters on the hydrolysis of cellulose with $\mathrm{RHNH}_{3} \mathrm{SO}_{4} \mathrm{H}$.

\begin{tabular}{|c|c|c|c|}
\hline \multirow{2}{*}{ Parameters } & \multirow{2}{*}{ Variants } & \multicolumn{2}{|c|}{ Glucose yield (mM \%) } \\
\hline & & at $6 \mathrm{~h}$ & at $13 \mathrm{~h}$ \\
\hline \multirow{3}{*}{ Variation of cellulose hydrolysis from different sources } & Pure cellulose & 98 & 10 \\
\hline & Cellulose from paper & 94 & 11 \\
\hline & Cellulose from rice husk & 93 & 18 \\
\hline \multirow{3}{*}{ Variation of metal chloride } & $\mathrm{LiCl}$ & 98 & 10 \\
\hline & $\mathrm{NaCl}$ & 91 & 9 \\
\hline & $\mathrm{KCl}$ & 90 & 13 \\
\hline \multirow{4}{*}{ Variation of solvent effects in $\mathrm{LiCl}$} & DMF & 98 & 11 \\
\hline & Cyclohexanol & 98 & 10 \\
\hline & Cyclopentanone & 91 & 15 \\
\hline & 1-Butanol & 89 & 18 \\
\hline \multirow{3}{*}{ Reusability of catalyst with $150 \mathrm{mg}$} & Fresh catalyst & 98 & 10 \\
\hline & 1st reuse & 93 & 11 \\
\hline & 2 nd reuse & 93 & 13 \\
\hline
\end{tabular}

The reaction was run over 13 hours at $120^{\circ} \mathrm{C}$ of hydrolysis temperature and $150 \mathrm{mg}$ of catalyst mass. 


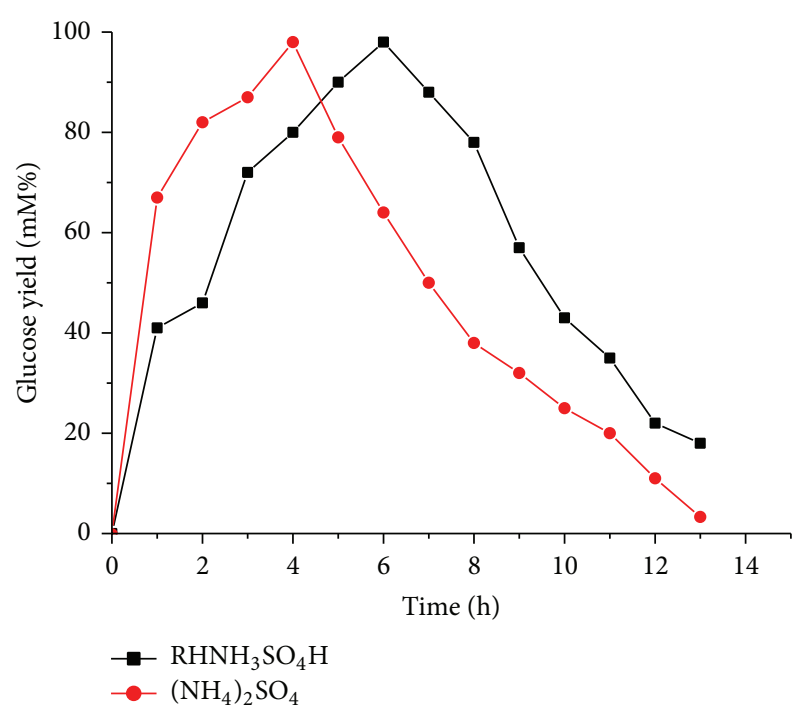

FIgURE 6: The hydrolysis of cellulose over $\mathrm{RHNH}_{3} \mathrm{SO}_{4} \mathrm{H}$ and $\left(\mathrm{NH}_{4}\right)_{2} \mathrm{SO}_{4}$ catalysts as a function of hydrolysis time. The hydrolysis conditions were the catalyst mass $150 \mathrm{mg}$ of $\mathrm{RHNH}_{3} \mathrm{SO}_{4} \mathrm{H}, 4.6 \mathrm{mmol}$ of $\left(\mathrm{NH}_{4}\right)_{2} \mathrm{SO}_{4}[18]$, at $120^{\circ} \mathrm{C}$.

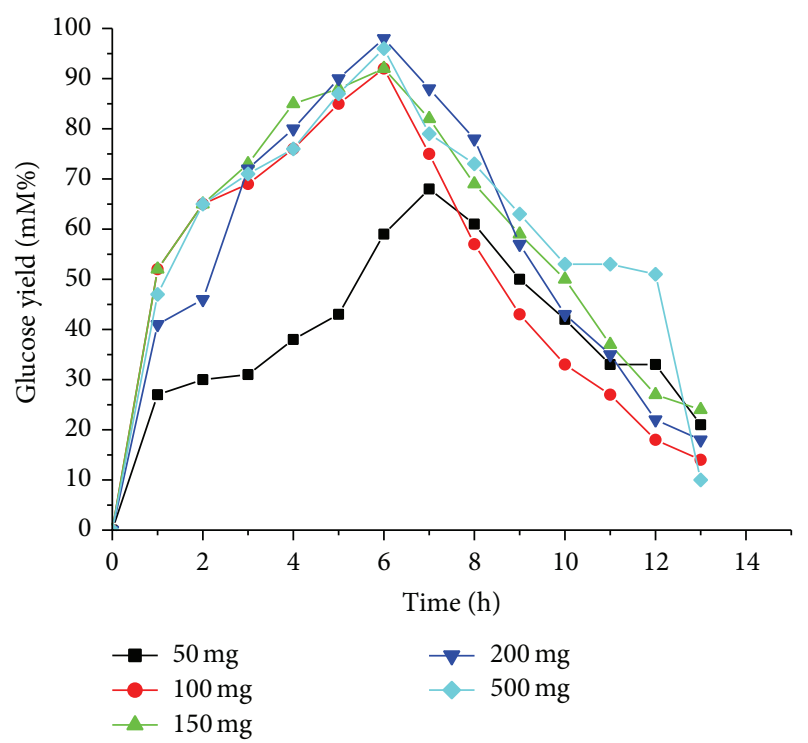

Figure 7: The hydrolysis of cellulose over $\mathrm{RHNH}_{3} \mathrm{SO}_{4} \mathrm{H}$, as a catalyst mass function. The hydrolysis conditions were $13 \mathrm{~h}$ hydrolysis time at $120^{\circ} \mathrm{C}$.

over these metal chlorides was increased according to the following order:

$$
\mathrm{LiCl}>\mathrm{NaCl}>\mathrm{KCl} .
$$

The chloride ion is playing a vital role in the solubility of cellulose. The metal ions are tightly linked with the carbonyl group of DMF while the chloride ions are left unencumbered. Thereby $\mathrm{Cl}^{-}$is highly active as a nucleophilic base and plays a major role by breaking up the inter- and intrahydrogen bonds [23]. This could make the hydrolysis of cellulose much easier.

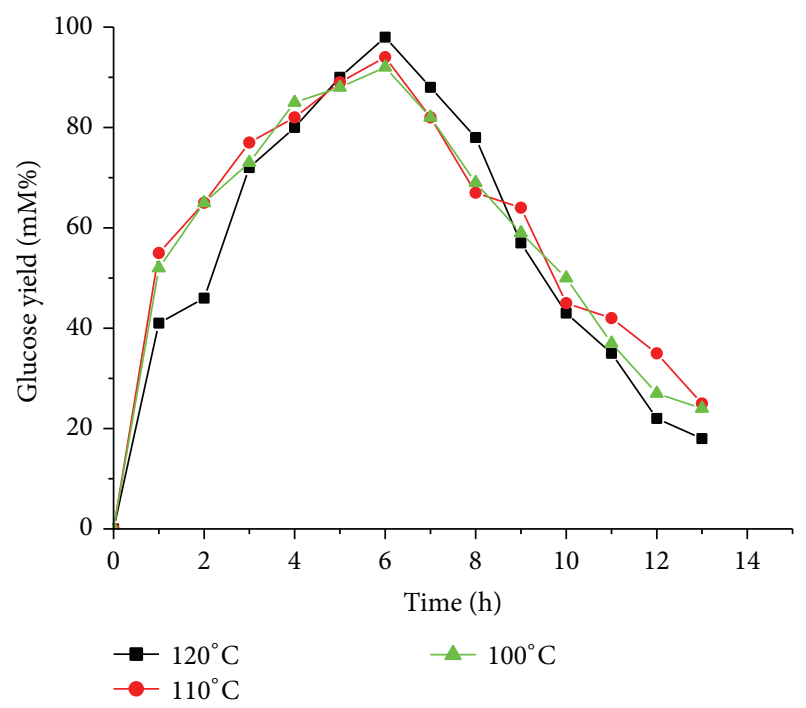

FIgURE 8: The hydrolysis of cellulose over $\mathrm{RHNH}_{3} \mathrm{SO}_{4} \mathrm{H}$, at different temperatures. The hydrolysis conditions were catalyst $150 \mathrm{mg}$ and $13 \mathrm{~h}$ as a hydrolysis time.

3.7.5. Catalyst Experiments on Cellulose from Different Sources. The effect of $\mathrm{RHNH}_{3} \mathrm{SO}_{4} \mathrm{H}$ on the cellulose extracted from different sources (waste of rice husk and waste office paper) is shown in Table 2. The run was done under the optimum conditions of the catalyst which were $150 \mathrm{mg}$ catalyst mass, reaction temperature of $120^{\circ} \mathrm{C}$, and $6 \mathrm{~h}$ reaction time. It was observed that the hydrolysis of the extracted cellulose from waste of RH was 93\%, while the hydrolysis of cellulose extracted from waste paper was $94 \%$. This clearly indicates that the catalyst was very active for the hydrolysis of cellulose from any sources.

3.7.6. Catalyst Recycle Experiments. Table 2 shows the $\mathrm{RHNH}_{3} \mathrm{SO}_{4} \mathrm{H}$ recycle experiments. After the first reaction was run using the catalyst at $120^{\circ} \mathrm{C}$ for $13 \mathrm{~h}$, the mixture, including the solid catalyst and the cellulose residue, was then filtered and washed with hot cyclohexanol and then with hot mixture of DMF and $\mathrm{LiCl}$ (repeated three times), and finally the catalyst was heated at $130^{\circ} \mathrm{C}$ for $24 \mathrm{~h}$. Next, fresh cellulose and DMF with $\mathrm{LiCl}$ were added to the catalyst obtained and a second run was conducted using the same procedure. As shown in Table 2, the product yield in the second run was similar to that in the first run, without any loss in the catalytic activity during the first $6 \mathrm{~h}$ of the hydrolysis. After the $6 \mathrm{~h}$ of the hydrolysis time a decrease in the cellulose hydrolysis was observed due to the hydrolysis of glucose to other products. These results indicated that catalytic performance was not lost in the course of the catalytic runs.

\section{Conclusion}

APTES was reacted with sodium silicate by following a purely homogenous route to form $\mathrm{RHAPrNH}_{2}$ which converted to the solid ammonium sulphate-like structure. According to 
the BET result the $\mathrm{RHNH}_{3} \mathrm{SO}_{4} \mathrm{H}$ had a $113 \mathrm{~m}^{2} \mathrm{~g}^{-1}$ specific surface area. The FT-IR clearly showed the presence of $-\mathrm{SO}_{2}-$ absorption bands at the expected range. The TEM shows that the $\mathrm{RHNH}_{3} \mathrm{SO}_{4} \mathrm{H}$ forms with a rod-like morphology. The diameters of the microrods are in the range of $0.1 \mu \mathrm{m}$ to $0.26 \mu \mathrm{m}$. The $\mathrm{RHNH}_{3} \mathrm{SO}_{4} \mathrm{H}$ was used to fully hydrolyze cellulose to other products at $120^{\circ} \mathrm{C}$ for $13 \mathrm{~h}$. The catalytic activity of the catalyst reaches the $98 \%$ of the glucose from cellulose and the selectivity was $100 \%$ at $6 \mathrm{~h}$, after the hydrolysis continues to form other products for up to $13 \mathrm{~h}$. The catalyst is simple to prepare and stable during the hydrolysis, and it can be used several times without significant loss of its catalytic activity.

\section{Conflict of Interests}

The authors declare that there is no conflict of interests regarding the publication of this paper.

\section{Acknowledgment}

The authors would like to thank Department of Chemistry, College of Science, Al-Muthanna University for partly supporting this work.

\section{References}

[1] F. Adam, H. E. Hassan, and K. M. Hello, "The synthesis of $\mathrm{N}$-heterocyclic carbene-silica nano-particles and its catalytic activity in the cyclization of glycerol," Journal of the Taiwan Institute of Chemical Engineers, vol. 43, no. 4, pp. 619-630, 2012.

[2] F. Adam, K. M. Hello, and M. R. Ben Aisha, "The synthesis of heterogeneous 7-amino-1-naphthalene sulfonic acid immobilized silica nano particles and its catalytic activity," Journal of the Taiwan Institute of Chemical Engineers, vol. 42, no. 5, pp. 843851, 2011.

[3] H. P. Wang, K. S. Lin, Y. J. Huang, M. C. Li, and L. K. Tsaur, "Synthesis of zeolite ZSM-48 from rice husk ash," Journal of Hazardous Materials, vol. 58, no. 1-3, pp. 147-152, 1998.

[4] D. Hoegaerts, B. F. Sels, D. E. de Vos, F. Verpoort, and P. A. Jacobs, "Heterogeneous tungsten-based catalysts for the epoxidation of bulky olefins," Catalysis Today, vol. 60, no. 3, pp. 209218, 2000.

[5] D. J. Macquarrie, "Direct preparation of organically modified MCM-type materials. Preparation and characterisation of aminopropyl-MCM and 2-cyanoethyl-MCM," Chemical Communications, no. 16, pp. 1961-1962, 1996.

[6] D. Brunel, "Functionalized micelle-templated silicas (MTS) and their use as catalysts for fine chemicals," Microporous and Mesoporous Materials, vol. 27, no. 2-3, pp. 329-344, 1999.

[7] F. Adam, K. M. Hello, and H. Osman, "Synthesis of mesoporous silica immobilized with 3-[(Mercapto or amino)propyl] trialkoxysilane by a simple one-pot reaction," Chinese Journal of Chemistry, vol. 28, no. 12, pp. 2383-2388, 2010.

[8] K. M. Hello, The heterogenation os saccharin, melamine, and sulfonic acid onto rice husk ash silica and their catalytic activity in esterification reaction [Ph.D. thesis], University Sains Malaysia, 2010.

[9] K. M. Hello, H. R. Hasan, M. H. Sauodi, and P. Morgen, "Cellulose hydrolysis over silica modified with chlorosulphonic acid in one pot synthesis," Applied Catalysis A: General, vol. 475, pp. 226-234, 2014.

[10] N. Andersen, Enzymatic hydrolysis of cellulose: experimental and modeling studies [PhD thesis], The Techical University of Denmark, Lyngby, Denmark, 2007.

[11] F. Adam and J.-H. Chua, "The adsorption of palmytic acid on rice husk ash chemically modified with $\mathrm{Al}$ (III) ion using the solgel technique," Journal of Colloid and Interface Science, vol. 280, no. 1, pp. 55-61, 2004.

[12] A. E. Ahmed and F. Adam, "Indium incorporated silica from rice husk and its catalytic activity," Microporous and Mesoporous Materials, vol. 103, no. 1-3, pp. 284-295, 2007.

[13] H. R. Hasan and M. H. Sauodi, "Novel method for extraction of cellulose from agricultural and industrial wastes," Indian Journal of Chemical Technology, vol. 9, no. 1, 2014.

[14] A. S. Amarasekara and B. Wiredu, "Aryl sulfonic acid catalyzed hydrolysis of cellulose in water," Applied Catalysis A: General, vol. 417-418, pp. 259-262, 2012.

[15] C. Breuil and J. N. Saddler, "Comparison of the 3,5-dinitrosalicylic acid and Nelson-Somogyi methods of assaying for reducing sugars and determining cellulase activity," Enzyme and Microbial Technology, vol. 7, no. 7, pp. 327-332, 1985.

[16] G. L. Miller, "Use of dinitrosalicylic acid reagent for determination of reducing sugar," Analytical Chemistry, vol. 31, no. 3, pp. 426-428, 1959.

[17] M. Mureseanu, A. Reiss, I. Stefanescu et al., "Modified SBA-15 mesoporous silica for heavy metal ions remediation," Chemosphere, vol. 73, no. 9, pp. 1499-1504, 2008.

[18] K. M. Hello, "Extraction of cellulose from waste palm fronds and its hydrolysis to glucose," Indian Journal of Chemical Technology. In press.

[19] M. Thommes, "Physical adsorption characterization of nanoporous materials," Chemie-Ingenieur-Technik, vol. 82, no. 7, pp. 1059-1073, 2010.

[20] F. Adam, K. M. Hello, and H. Osman, "The heterogenation of melamine and its catalytic activity," Applied Catalysis A, vol. 382, no. 1, pp. 115-121, 2010.

[21] E. J. Nassar, C. R. Neri, P. S. Calefi, and O. A. Serra, "Functionalized silica synthesized by sol-gel process," Journal of NonCrystalline Solids, vol. 247, pp. 124-128, 1999.

[22] V. Luca, L. Kevan, C. N. Rhodes, and D. R. Brown, "A synthetic Zn-substituted smectite clay alkylation catalyst," Clays and Clay Minerals, vol. 27, pp. 515-519, 1992.

[23] A.-L. Dupont, "Cellulose in lithium chloride/,$N$-dimethylacetamide, optimisation of a dissolution method using paper substrates and stability of the solutions," Polymer, vol. 44, no. 15, pp. 4117-4126, 2003. 

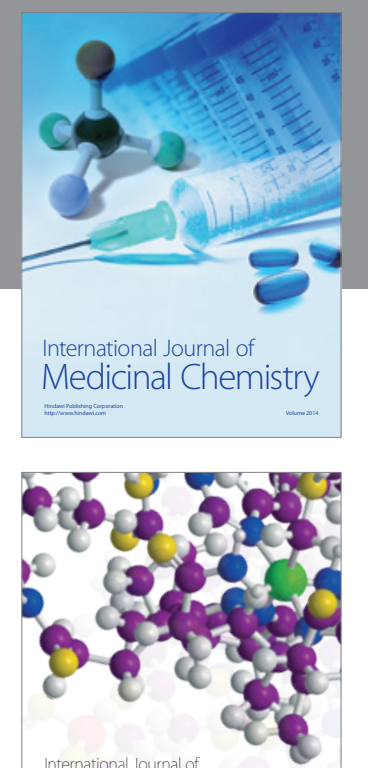

\section{Carbohydrate} Chemistry

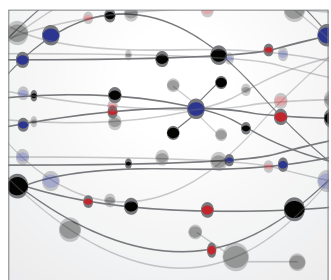

The Scientific World Journal
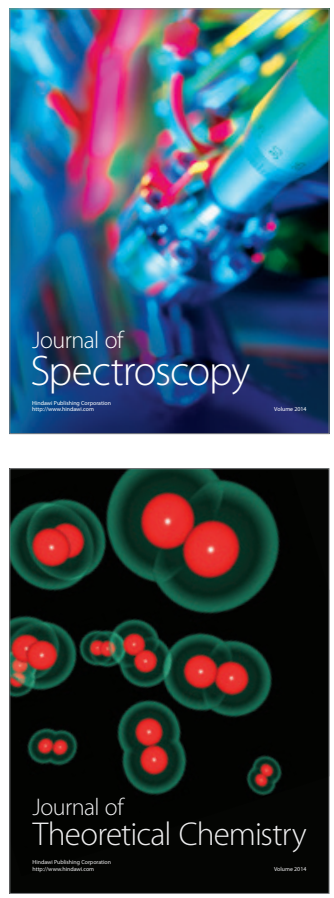
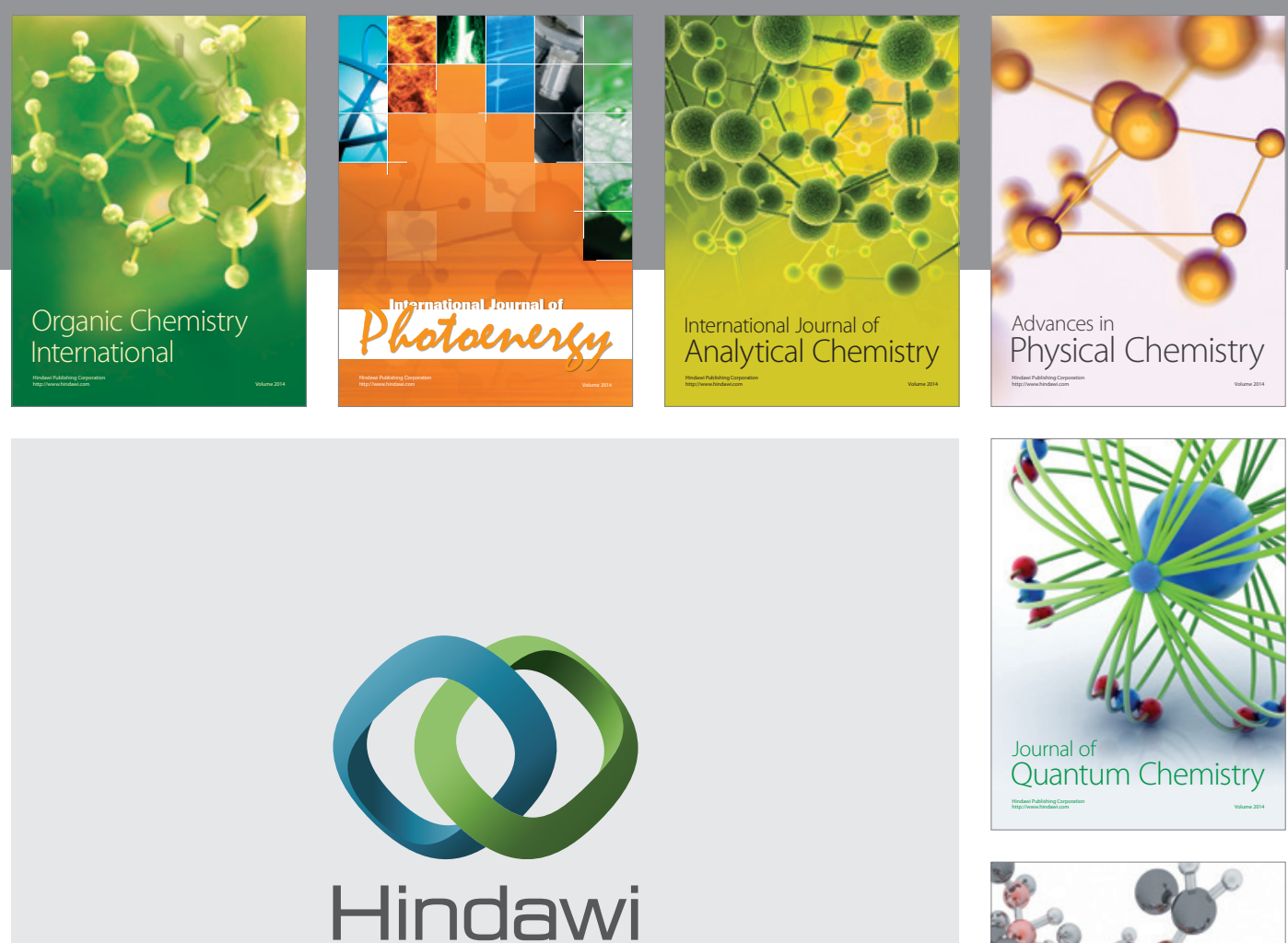

Submit your manuscripts at

http://www.hindawi.com

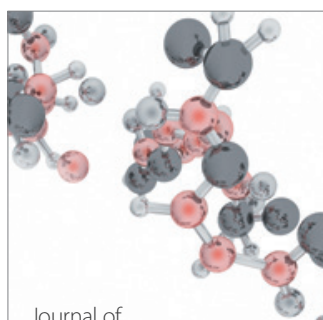

Analytical Methods

in Chemistry

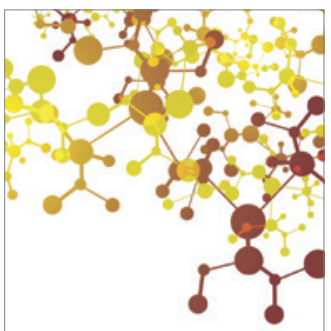

Journal of

Applied Chemistry

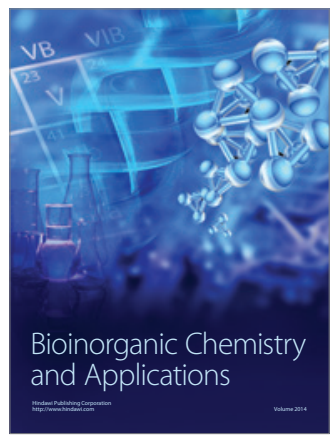

Inorganic Chemistry
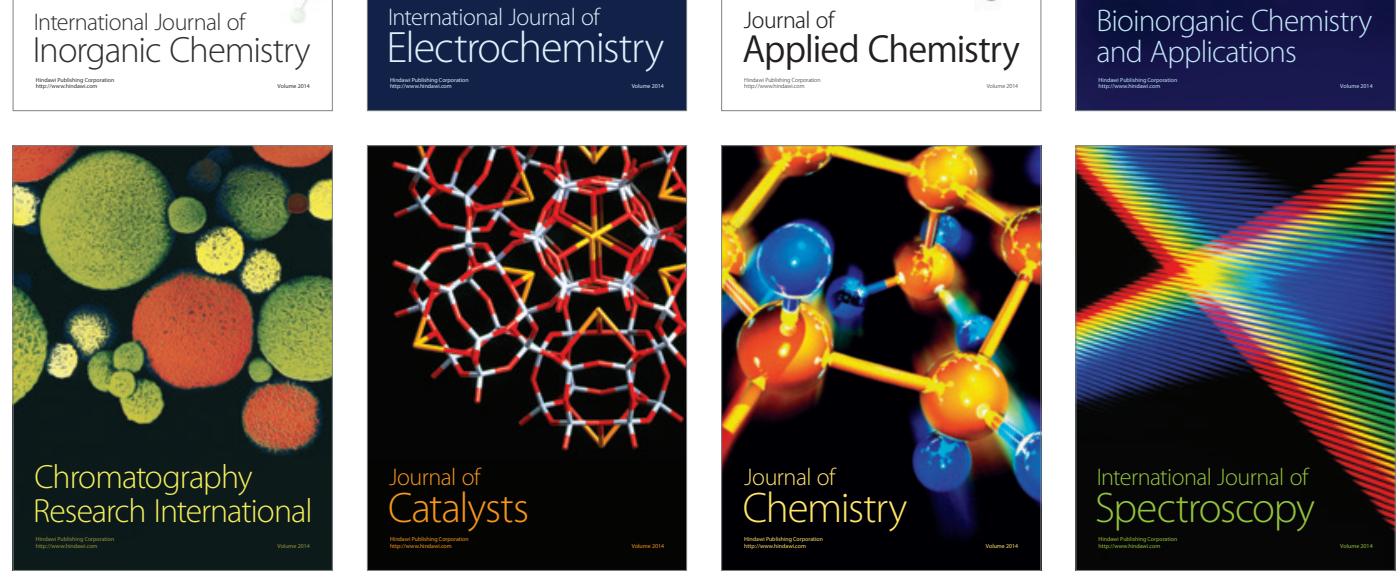